\title{
Alcohol-exposed? Next
}

$\mathrm{T}$ uesday morning case conference with the team. Social services refers us yet another 10year-old boy at risk of losing his long-term foster care placement. We'll call him Johnny. Highlights in the referral notes include the following:

Aggressive toward the foster parents' biological children. Constant calls from school about his "unruly behaviour." Biological mother reportedly "an addict." No information available on his biological father. Johnny first taken into temporary foster care at 10 months of age. Anonymous call to police that children at risk in a "crack house." Multiple adults in the house; drugs; bio mom not there; Johnny found in soiled diapers but otherwise "physically okay." Johnny then placed in kinship care with visits with his biological mother as she worked on "getting her life back together." Questions arose about sexually inappropriate behaviour in the kinship home, nothing clarified. Kinship parents split. Johnny back into temporary foster care at four years of age. Long-term foster care placement found at six years. Whereabouts of biological mother currently unknown.

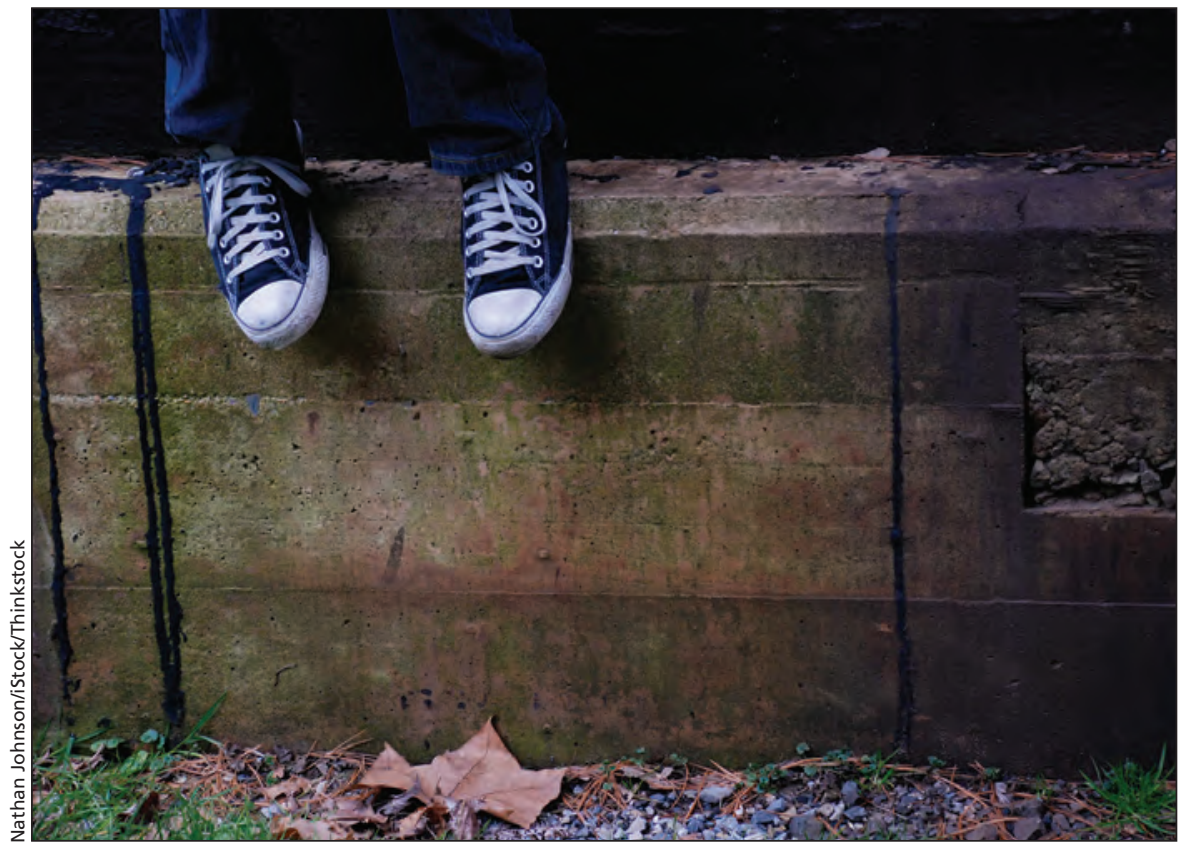

bedtime at 9 on a school night, but he's up to 1 am most nights. He keeps sneaking out of his room, into the pantry to steal food even though we give him a good supper. Then he'll pull out the electronics. He's even left the house in the middle of the night! We don't trust him around our eight-year-old daughter. Or our six-year-old son. He

\section{"The school caught him twice taking a knife to school. I don't know how much longer we can do this."}

The team social worker meets with the foster mother while we sit behind the one-way mirror. Johnny plays on the Wii in the waiting room. The foster mother talks about Johnny's many "challenging behaviours."

"He never does what he's told. Gives attitude with even simple requests, just asking him to clean up his dishes. Bedtime's a nightmare. We set will rip a toy out of our son's hands seemingly just to get a reaction. When I tell him to take a time-out for his behaviour, he screams that he hates me and calls me a bitch. The school caught him twice taking a knife to school. I don't know how much longer we can do this."

"I tried to get more information from social services about his family. You know that mom was a drug addict, although they can't find her. The social service worker told me that they also think that mom was a drinker. There is apparently a lot of alcoholism in that family. Social services spoke with the maternal grandmother, and she said the likely father is a big drinker and violent and the grandmother was pretty sure that he and the mother were both drinking during the pregnancy. The worker says he might have fetal alcohol syndrome [FAS]. So I went to an information night about FAS at our community centre. Johnny sounds so much like those kids. Sometimes I think Johnny doesn't know right from wrong. He just does things. They said that behavioural modification doesn't work with these kids and I've tried everything with Johnny; nothing seems to work. I've tried praising, we have clear limits in our home, time-out has been a disaster. Then I heard about that FAS youth that killed his social worker. I don't feel safe in my own home, and my children ..."

One of our staff asks, "So should we 
make a referral to the FAS clinic?"

I think back about that kid a couple of weeks ago — the same story arc. A loaded history including parental mental illness and addiction, early abuse and neglect, changing caregivers in the early years, interrupted relationships all these factors adversely affecting this developing child ... and then reducing it all to this single exposure, a single diagnosis. FAS.

So what's next, Johnny? You'll get a four-digit FAS diagnostic code. You'll get special school coding. Maybe you'll get special mentorship or access to special programs. We will lower our expectations of you. It's not your fault. You apparently can't tell right from wrong. I have been told our evidence-based therapies for your behaviours don't work for kids with FAS, so we won't try them.

Remember, your new label is not supposed to incriminate your mom. Maybe your mom didn't drink during pregnancy. It was not a "reliable, confirmed drinking history." Maybe she only did drugs. Maybe you were just exposed to a lot of other shit. Maybe you inherited some bad genes. Johnny, I'm sorry, but I am not that smart. I don't know what got you into this predicament. I'm not sure you are going to benefit from your new label. I'm not sure what's in store for you. Maybe I am doing you more harm than good. We'll see what the FAS clinic comes up with. I hate this screening and then $\mathrm{f} * * *$ ing random punting. Our next case is up ...

\section{John D. McLennan MD}

Child Psychiatry Consultant, Cumming School of Medicine, University of Calgary, Calgary, Alta.

CMAJ 2015. DOI:10.1503/cmaj.150041

Editor's note: Johnny is a composite of many patients who may or may not have fetal alcohol syndrome.

\section{A false dichotomy}

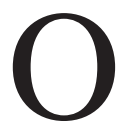
$\mathrm{n}$ the first day of medical school, I was told "medicine is an art and a science." Since then, that phrase, or some variation of it, has been repeated to me at least weekly. My teachers have portrayed art and science as a dichotomy, equating science with factual, evidencebased truth while invoking the art of medicine to explain how epidemiologic factors do not apply to particular patients and how physicians must deal with uncertainty. However, this is a false dichotomy: art and science have much more in common than is suggested by the binary phrase "the art and science of medicine."

Recently, a number of medical educators have identified problems with how the arts, social sciences and humanities are addressed in medical school curricula. There is thus growing interest in developing more rigorous and nuanced approaches to the art of medicine. ${ }^{1}$ In contrast, the way in which science is taught in medical school is not generally seen as problematic. But the construction of science as facts and evidence is an oversimplification that must also be considered by medical educators. The equating of science solely with statements of truth and guidelines eliminates the complexity and beauty that draw many scientists to science - and that drew me to chemistry.

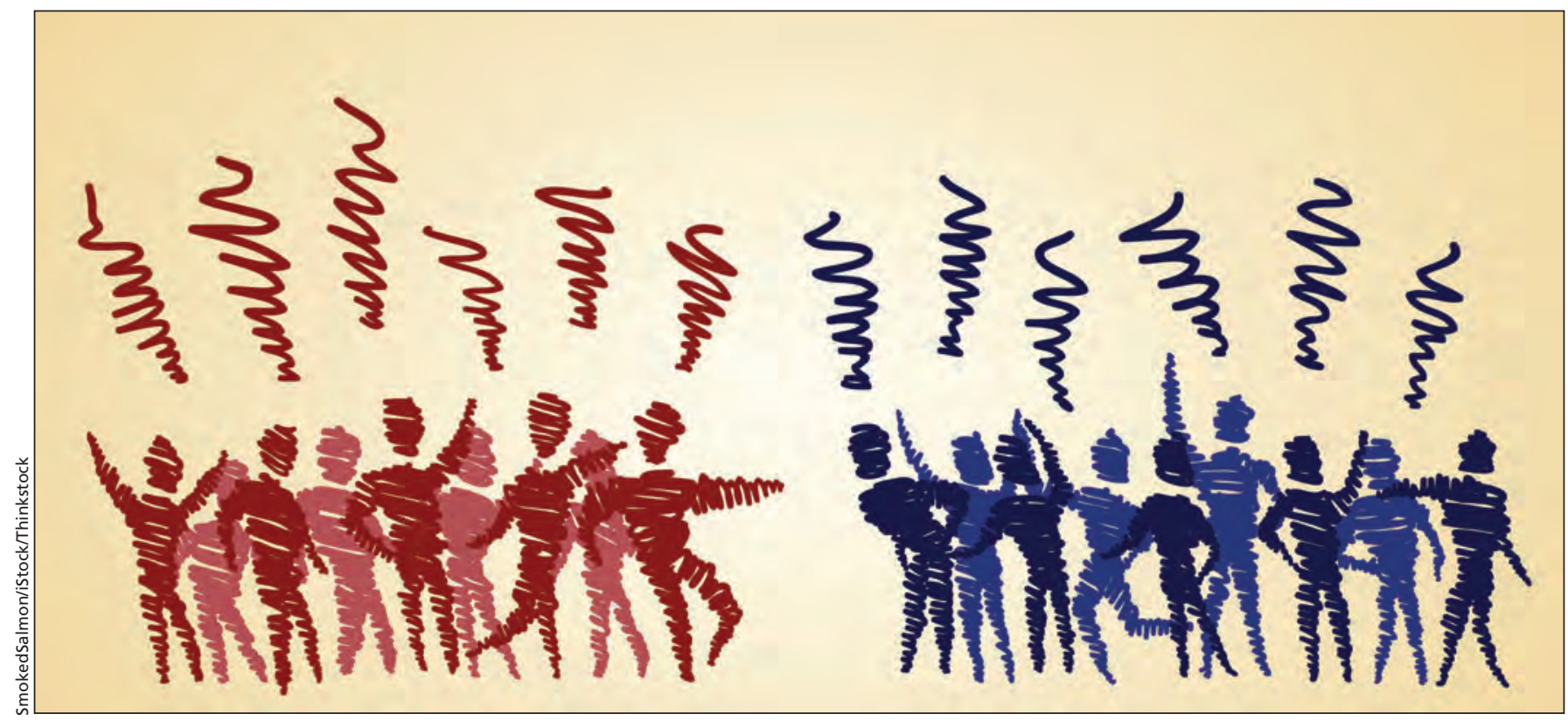

